SiF 2020 - The $11^{\text {th }}$ International Conference on Structures in Fire

The University of Queensland, Brisbane, November 30 - December 2, 2020

\title{
LIFETIME ECONOMICALLY OPTIMUM POSITION OF STEEL REINFORCEMENT IN A CONCRETE COLUMN EXPOSED TO NATURAL FIRE
}

\author{
Shuna $\mathrm{Ni}^{1}$, Ruben Van Coile ${ }^{2}$, Negar Elhami Khorasani ${ }^{3}$, Danny Hopkin ${ }^{4}$, Thomas Gernay ${ }^{5}$
}

\begin{abstract}
This paper incorporates a probabilistic fire loss assessment method for reinforced concrete structures into a cost-benefit analysis to optimize a structural fire design. Economic losses in case of failure and survival of the structure are both quantified with, in the latter case, an estimate of the damage and repairs costs. As a case study, a cost-benefit optimization of the position of rebars in a concrete column is investigated. The column response in fire is evaluated using finite element simulations in SAFIR. Variations in cover thickness result in variations in failure probabilities and, for cases where no failure occurs, variations in repair costs due to heat penetration and residual out-of-plane deformation of the column. The optimum cover thickness is the one that offers the best trade-off between the various repair costs across the range of likely fire intensity levels. This optimum is sensitive to repair decisions such as the tolerance on the acceptable residual out-of-plane deformation after a fire. For the studied cases, the optimum cover thickness is smaller in slender columns than in stocky columns due to greater out-of-plane deformations in the former.
\end{abstract}

Keywords: Fire; probabilistic loss estimation; cost-benefit analysis; concrete columns; cover optimization

\section{INTRODUCTION}

Adequate fire safety requires that the building's risk profile with respect to fire exposure is tolerable, and that societally cost-effective safety measures are implemented [1]. The tolerability evaluation is best done holistically, taking into account the combined fire performance of all the building's fire safety features. In the end, an explicit tolerability evaluation elucidates the range of potential consequences and their occurrence frequencies for the design, and confirms that these are acceptable to the stakeholders under the condition that further investment is too costly. The consideration that further investment is not costeffective is a direct implementation of the As Low As Reasonably Practicable (ALARP) requirement, demonstrating that the residual risk level is ALARP.

A case specific demonstration of tolerability and ALARP is however exceedingly rare. Most buildings are constructed through consideration of prescriptive design guidance, either directly or through engineered 'alternative solutions'. Achieving tolerability and ALARP for those buildings is assumed based on the application of the design guidance itself, placing great importance on the appropriateness of this guidance. The design guidance should result in a building for which the residual risk is approximately ALARP, i.e., further safety investments are suboptimal, provided that guidance is applied within its intended scope.

\footnotetext{
${ }^{1}$ Assistant Professor, Utah State University

e-mail: shuna.ni@usu.edu, ORCID: https://orcid.org/0000-0002-8795-176X

${ }^{2}$ Assistant Professor, Ghent University

e-mail: Ruben.VanCoile@UGent.be, ORCID: https://orcid.org/0000-0002-9715-6786

${ }^{3}$ Assistant Professor, University at Buffalo

e-mail: negarkho@ buffalo.edu, ORCID: https://orcid.org/0000-0003-3228-0097

${ }^{4}$ Visiting Professor, University of Sheffield

e-mail:danny.hopkin@@@ofrconsultants.com, ORCID: https://orcid.org/0000-0002-2559-3581

${ }^{5}$ Assistant Professor, Johns Hopkins University

e-mail: tgernay@jhu.edu, ORCID: https://orcid.org/0000-0002-3511-9226

https://doi.org/10.14264/985c79e
} 
The above observation is not restricted to fire engineering. As stated by Rackwitz, design optimization forms the basis of code calibration in structural engineering [2]. When adopting such an approach, the lifetime costs and benefits of safety investments are balanced to derive optimum values for the design. These optima can then be either listed directly in design guidance as part of prescriptive (tabulated) recommendations or can be generalized towards target safety levels. In fire safety engineering, efforts towards lifetime cost optimization (LCO) have only been explored recently. For example, De Sanctis and Fontana derived the optimum egress width for compartments in multi-story commercial premises with a single compartment exit [3]. In structural fire safety engineering, LCO based methods are applied by Hopkin et al. [10] to derive optimum insulation thicknesses for protected steel beams.

However, most current studies related to the design optimization calculate the lifetime costs, particularly the repair cost, only based on a binary damage criterion, failure or no failure [4-6], which may not be suitable for some scenarios where a finer degree of granularity in defining fire damage is required, e.g., for reinforced concrete $(\mathrm{RC})$ structures that usually do not collapse under fire but require significant repair efforts for continued use. To overcome this limitation, this paper incorporates a recently developed fire loss estimation method [7] into a lifetime cost optimization. The loss estimation method addresses gradual levels of damage states and the corresponding repair efforts, in addition to a binary failure/no failure criterion, thus providing a more refined estimate of the repair costs. In this paper, the general formulation of the costbenefit analysis is introduced first; then, the fire loss estimation method is described. The theory is then applied to the problem of cover thickness optimization of RC columns in the fire situation. Finally, the discussion is expanded to show the effects of occupancy types and column slenderness on the derived optimum cover thickness.

\section{METHOD}

\subsection{Cost-benefit analysis for fire design optimization}

Cost-benefit evaluations in structural engineering are commonly derived from [2], with further reference to [8]. These formulations were adapted to consider fire exposure in $[4,9,10]$. Following the formulation as described by Hopkin et al. [10], the lifetime cost is given by Eq. 1, with constituent terms including the total building construction and maintenance cost, $\mathrm{C}$; the obsolescence cost, $\mathrm{A}$; the adverse event (nonstructural) direct and indirect material damages, $\mathrm{D}_{\mathrm{M}}$; the adverse event loss to human life and limb, $\mathrm{D}_{\mathrm{L}}$; and the adverse event (structural) reconstruction and repair cost after fire, $\mathrm{D}_{\mathrm{R}}$. The lifetime cost and its constituent terms are functions of a vector $\boldsymbol{p}$ of design parameters $p_{i}$. Minimizing the overall lifetime cost corresponds with finding the combination of design parameters for which the lifetime cost's partial derivatives are zero, i.e., Eq. 2. For completeness, Eq. 2 should be solved with considerations to avoid obtaining local minima or maxima. Furthermore, when considering physical constraints to the design parameters, the global minimum lifetime cost may correspond with the limiting values of the design parameters, which do not conform to Eq. 2. For simple cases in accordance with the current state-of-theart, the above issues are generally not a concern as the lifetime cost function Y can readily be visualized, confirming the global minimum.

$Y=C+A+D_{M}+D_{L}+D_{R}$

$\frac{\partial Y}{\partial p_{i}}=0 \forall i$

The construction cost $C$ is commonly modelled as the sum of a base construction cost $C_{0}$ and a safetyinvestment $\operatorname{cost} C_{l}$. Only the latter cost is considered as a function of the design parameter vector $\boldsymbol{p}$. The obsolescence cost $A$ is commonly specified through an obsolescence rate $\omega$, discounted to present net value through the continuous discount rate $\gamma$. Considering (from a practical perspective) an infinite time horizon for the optimization, the present net values for $C$ and $A$ are given by Eq. 3 and Eq. 4 .

$C=C_{0}+C_{1}(p)$ 
$A=C \frac{\omega}{\gamma}$

The damage terms $D_{M}, D_{L}$, and $D_{R}$ relate to damages incurred in case of adverse events. First of all, such damages can be incurred in case of structural failure in normal design conditions. Considering a yearly probability of structural failure $P_{f, 0}$, the associated annualized costs are specified through Eq. 5-7, with $C_{M, 0}$ the material damage incurred in case of normal design situation failure, and $C_{L, O}$ and $C_{R, O}$ the corresponding human losses and repair costs. These costs are here considered as deterministic (expected) values. The effect of variability in the incurred damages is considered through the tolerability assessment.

$D_{M, 0}=\frac{P_{f, 0}}{\gamma} C_{M, 0}$

$D_{L, 0}=\frac{P_{f, 0}}{\gamma} C_{L, 0}$

$D_{R, 0}=\frac{P_{f, 0}}{\gamma} C_{R, 0}$

In the context of this paper, fire-induced damages are investigated. It is considered here that other damage terms (related to, for example, flooding) can be neglected, or more precisely: that these other damage terms are not $\boldsymbol{p}$-dependent. The fire-related damage terms are specified below, where $\lambda_{f i}$ is the occurrence rate of structurally significant fires, $P_{f, f i}$ is the (conditional) probability of structural failure (collapse) in case of fire. With respect to the incurred losses, a distinction can be made between situations where the structure collapses during fire and situations where the structure survives up to burnout. Hence, a distinction is made for the incurred costs as well, with the index ' $f$ ' corresponding with failure and the index ' $n f$ ' indicating the situation where the structure maintains stability up to and including burnout.

$$
\begin{aligned}
& D_{M, f i}=\frac{\lambda_{f i}}{\gamma}\left(P_{f, f i} C_{M, f i, f}+\left(1-P_{f, f i}\right) C_{M, f i, n f}\right) \\
& D_{L, f i}=\frac{\lambda_{f i}}{\gamma}\left(P_{f, f i} C_{L, f i, f}+\left(1-P_{f, f i}\right) C_{L, f i, n f}\right) \\
& D_{R, f i}=\frac{\lambda_{f i}}{\gamma}\left(P_{f, f i} C_{R, f i, f}+\left(1-P_{f, f i}\right) C_{R, f i, n f}\right)
\end{aligned}
$$

Summation of Eq. 3-10 gives an extensive formulation of the total lifetime cost $\mathrm{Y}$ in accordance with Eq. 1, considering a vector $\boldsymbol{p}$ of design variables. Depending upon the case, the vector of design parameters $\boldsymbol{p}$ will influence the failure probabilities and/or the expected values of the incurred costs for Eq. 5-10. In agreement with current state-of-the-art applications, adoption of a number of simplifying assumptions allows a reduction in the equations considerably. Firstly, current LCO for structural fire engineering (SFE) considers only a single design variable $p$ for the optimization. Secondly, the probability of structural failure in normal design conditions can be considered negligible, i.e., $P_{f, 0} \approx 0$, or to the same effect, the failure probability and costs incurred in case of normal design failure can be considered independent of the fire design optimization parameter $p$. In that case, the contribution of normal design failure to the lifetime cost can be substituted by a constant value $a$. The lifetime cost now reduces to Eq. 11, where the index ' $p$ ' has been introduced to denote $p$-dependency.

$Y=a+C_{0}\left(1+\frac{\omega}{\gamma}\right)+C_{1, p}\left(1+\frac{\omega}{\gamma}\right)+D_{M, f i, p}+D_{L, f i, p}+D_{R, f i, p}$

Further assumptions can be made to simplify the formulation for specific cases. For example, where the design variable $p$ applies to a member that is not critical to the stability of the entire structural assembly (e.g., due to redundancy and robustness of the structure), it may be assumed that incurred costs due to complete building failure are negligible. In other words, if structural stability up to burnout is readily ensured, the term $P_{f, f i} \approx 0$. Rebasing the lifetime cost to $Y_{n l}$, leaving only the $p$-dependent terms, results in Eq. 12.

$Y_{n 1}=C_{1, p}\left(1+\frac{\omega}{\gamma}\right)+\frac{\lambda_{f i}}{\gamma}\left(C_{M, f i, n f, p}+C_{L, f i, n f, p}+C_{R, f i, n f, p}\right)$ 
If, in addition to the above, the design parameter does not significantly affect the cost of the design, then $C_{1, p} \approx 0$. Rebasing and renormalizing the cost to $Y_{n, 2}$ results in Eq. 13 .

$Y_{n 2}=C_{M, f i, n f, p}+C_{L, f i, n f, p}+C_{R, f i, n f, p}$

If furthermore the fire is contained to the storey of origin, and knowing that stability up to burnout is maintained, the nonstructural material losses and human losses can reasonably be considered independent of structural fire design parameters. The lifetime cost can then be rebased to the basic formulation of Eq. 14, i.e., the lifetime cost of the design is in such cases fully dependent on the reconstruction and repair cost in the wake of a fire.

$Y_{n 3}=C_{R, f i, n f, p}$

\subsection{Fire loss estimation}

The cost-benefit analysis requires the estimation of fire loss. A framework [7] has been proposed to estimate the direct fire loss in concrete structures. The framework considers different possible fire scenarios within the building, corresponding to different possible ignition locations. For a given fire location, the framework applies a four-step procedure, which parallels the PEER methodology [11], including fire hazard analysis, fire-thermo-mechanical analysis, damage analysis, and loss analysis.

The fire hazard analysis first calculates the probability of having a severe fire in a building and the conditional probability of fire occurrence in different compartments. These probabilities are used to integrate the losses associated with different fire locations, as shown by the loop in Figure 1. The fire hazard analysis then provides the associated distribution of the intensity measure (IM) of fire hazards that represents the hazard severity. The fire load density $\mathrm{q}_{\mathrm{f}}$ in a compartment (in $\mathrm{MJ} / \mathrm{m}^{2}$ of floor area) is used as IM [12].

Given a location of fire fiL $\mathrm{L}_{\mathrm{i}}$ and a fire load $\mathrm{q}_{\mathrm{f}}$, a fire-thermo-mechanical analysis is conducted to obtain the engineering demand parameters (EDPs) that are used to quantify the damage. The analysis incorporates the uncertainties from the fire, heat transfer, and mechanical models. For each fire location, probabilistic firethermo-mechanical analyses of the building are conducted for different values of the fire load $\mathrm{q}_{\mathrm{f}}$. The analyses yield probability density distributions of the defined EDPs.

Based on the EDPs, the damage analysis quantifies the probability associated with failure, as well as the probability associated with each damage state for the building's components. This probability distribution for the damage measure (DM) is conditional on a specific fire load $\mathrm{q}_{\mathrm{f}}$ and fire location fiL $\mathrm{L}_{\mathrm{i}}$. Finally, the loss analysis estimates the replacement or repair cost. This estimation is based on loss functions that represent the probabilistic distributions of the repair costs for each component at each damage state, including structural components, nonstructural components, and content, in the fire exposed area and outside this area. The repair cost is estimated for each fire location. The total fire loss for a building is the weighted summation of the fire loss at each fire location, where the weights account for the probabilities of the different fire scenarios (i.e. allocation of the annual ignitions amongst compartments).

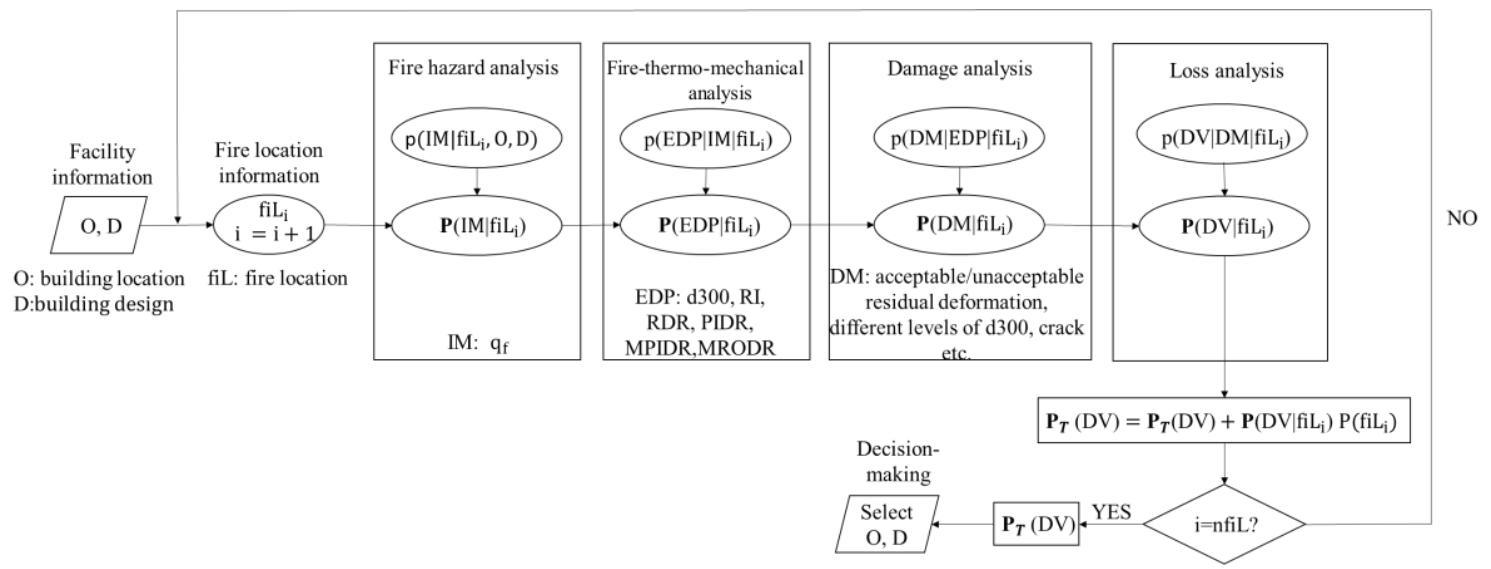

Figure 1. Probabilistic loss assessment for buildings under fire [7] 


\subsection{Optimization of the cover thickness of a column}

The above described methods are implemented in this paper to optimize the cover thickness of RC columns. As the full fire-induced collapse of RC buildings is rare, it is assumed as a simplification that $P_{f, f i} \approx 0$. This assumes that the failure of a column in a fire compartment does not lead to the failure of the building. Meanwhile, the change of cover thickness by displacing the rebars (at constant section size) does not change the construction cost for a column, hence $C_{1, p}=0$. Assuming that the fire is contained to the fire compartment where the target column is located and knowing that stability up to burnout is maintained, the nonstructural material losses and human losses can reasonably be considered independent of the column cover thickness. Therefore, the optimization of cover thickness could be conducted based on Eq. 14 that has been simplified to only include the expected repair cost, $C_{R, f i, n f, p}$. The framework described in Section 2.2 is used to estimate the expected repair cost in Eq. 14, but without considering the uncertainties in fire locations. The estimation of the expected repair cost for a single column includes both failure (of the column) and nonfailure cases.

The optimization is conducted using the numerical method, and the optimal design parameter is identified by visualizing the variation of the repair cost with the design parameter. The optimum cover thickness is the one that minimizes the repair cost.

\section{ANALYSES}

\subsection{Description of the columns}

The cover thickness of two columns (Column A and Column B) are optimized to illustrate how to use the method of Section 2. Columns A and B are assumed to be located in a $21 \mathrm{~m}$ x $21 \mathrm{~m}$ fire compartment, with maximum opening factor equal to $0.043 \mathrm{~m}^{1 / 2}$. The mean compressive strength of concrete is $30 \mathrm{MPa}$, while the steel rebar's mean yield strength is $400 \mathrm{MPa}$. The dimension and reinforcement details of the two columns are shown in Figure $2 \mathrm{a}$ and $2 \mathrm{~b}$. The column height is $3.867 \mathrm{~m}$. The reference cover thickness is $40 \mathrm{~mm}$ for Column A and $30 \mathrm{~mm}$ for Column B. The columns are assumed as pinned-pinned with an axial load at the top of the column, as shown in Figure 2c. Column A is exposed to natural fire on three sides, with a reference gravity load (Eurocode combination in the fire situation) of $992 \mathrm{kN}$. Column B is exposed to natural fire on four sides, with a reference gravity load of $1984 \mathrm{kN}$. A sinusoidal geometric imperfection with $1 / 400 \mathrm{~h}$ at the middle height is imposed to the columns, where $\mathrm{h}$ is the height of the column.

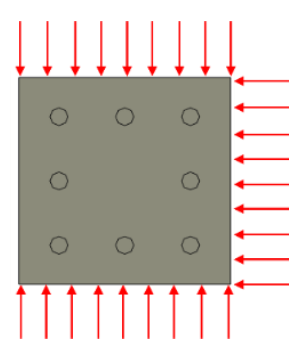

(a) Column A, $350 \mathrm{~mm} \times 350 \mathrm{~mm}$, 8 bars of $30 \mathrm{~mm}$ diameter

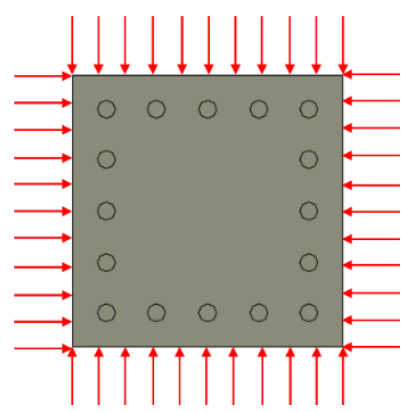

(b) Column B, $450 \mathrm{~mm} \times 450 \mathrm{~mm}$, 16 bars of $30 \mathrm{~mm}$ diameter

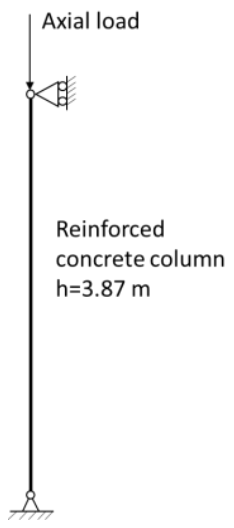

(c) Mechanical boundary condition

Figure 2. Dimension and thermal boundary condition of RC columns

\subsection{Description of EDPs, DSs, fragility functions, and loss functions}

The columns are subject to natural fires inclusive of a cooling phase. A failure criterion is first used to identify whether a column fails. Here, failure is characterized by the sudden and large increase in deformation. If the column fails, the cost of reconstruction of the column is adopted. If the column does not 
fail, the repair cost related to each damage state of a column is calculated based on fire-specific EDPs, DSs, fragility functions and loss functions.

It is recognized that fire damage is caused by both thermal action (i.e., thermally-induced degradation of the material) and mechanical action (i.e., thermally-induced deformations and forces in the structure). Therefore, two EDPs are selected to assess the damage in the members. The first EDP is the heat penetration depth of the $300^{\circ} \mathrm{C}$ isotherm in the section, to address the material damage due to heat penetration [7]. Different repair actions are required as a function of the heat penetration. The second EDP is the maximum residual out-of-plane deformation ratio (MRODR), i.e., the ratio of the maximum residual out-of-plane deformation over column height, to address the fire damage related to residual deformations. A limit in the out-of-plane deformation could avoid the detrimental effects in terms of mechanical resistance and stability in transient and service stages, the service performance during the use of a building, and guaranteeing the compatibility for the erection of the structure and its nonstructural components. ENV 13670-1 [13] recommends that the structural deviation of a column should be less than the larger of $1 / 300 \mathrm{~h}$ and $15 \mathrm{~mm}$. Such a threshold value may be different for different purposes; therefore, various threshold values $(1 / 300 \mathrm{~h}$, $1 / 500 \mathrm{~h}$, and $1 / 700 \mathrm{~h}$ ) are investigated in this paper. A column has to be replaced if its MRODR value is greater than the selected threshold value; otherwise, no repair actions are required.

The damage states of the column, corresponding to different levels of repair efforts, are mapped to different EDP thresholds. The damage related to the heat penetration of the $300{ }^{\circ} \mathrm{C}$ isotherm has four states, which has been described in details in [7]. The damage related to the residual out-of-plane deformation has only two states, i.e., MRODR exceeding the threshold value (replacement) or not (no action). To consider the uncertainties inherent to the post-fire evaluation, the threshold values are taken as probabilistic variables. The lognormal distribution of the lower threshold of each damage state, as a probabilistic function of the EPD, is the fragility function that represents the probability that a component reaches or exceeds a specified damage state [7].

The repair cost corresponding to each damage state is assumed to follow a lognormal distribution, with the mean value estimated from data in the Concrete \& Masonry Costs (RSMeans, 2019 [14]) and the COV ranging from 0.6 to 0.8 based on earthquake engineering data [15]. Table 4 lists the mean repair cost of the two columns with the reference cover thicknesses for the damage related to heat penetration. As the cover thickness changes, the repair cost varies slightly for DS1, DS2, and DS3 while the costs for DS4 remain the same, corresponding to the reconstruction (demolition and replacement) of a column due to extensive damage from the heat penetration, which is also the cost for scenarios when a column fails or experiences extensive out-of-plane deformation leading to its replacement.

Table 1. Repair cost for the EDP of heat penetration (d300) for columns exposed to fire

\begin{tabular}{lrrrr} 
& DS1 (\$) & DS2 (\$) & DS3 (\$) & DS4 (\$) \\
\hline Column A, 40 mm & 143 & 725 & 1,240 & 7,329 \\
Column B, 30 mm & 246 & 1,179 & 2,461 & 12,852 \\
\hline
\end{tabular}

\subsection{Identification of probabilistic parameters}

This section studies the sensitivities of column damage to variables related to fire analysis, thermal analysis, and structural analysis, including opening factor of a fire compartment, concrete thermal conductivity, concrete density, dead load, live load, model effect, retention factor of concrete compressive strength at high temperature, and retention factor of steel yield strength at high temperatures.

The uncertainty in the opening factor is adopted from the JCSS model [16], $0=0_{\max }(1-\zeta)$, where $0_{\max }$ is the maximum possible opening factor assuming all the window glass is immediately broken when fire breaks out. $\mathrm{O}_{\max }=0.043 \mathrm{~m}^{1 / 2}$ is assumed for the target compartment. $\zeta$ is a random variable following a truncated (cut off at 1.0) lognormal distribution with a mean of 0.2 and a standard deviation of 0.2.

The concrete thermal conductivity can be chosen between a lower $(\alpha=0)$ and an upper $(\alpha=1)$ limit, which follow the recommendation of Eurocode [17]. It is assumed that $\alpha$ follows a uniform distribution with a 
range from 0 to 1 . The characteristic range of normal-weight concrete density ranges from $2240 \mathrm{~kg} / \mathrm{m}^{3}$ to $2400 \mathrm{~kg} / \mathrm{m}^{3}$ [18]. For the thermal analysis, it is assumed that the density of normal-weight concrete follows a uniform distribution with a range from $2240 \mathrm{~kg} / \mathrm{m}^{3}$ to $2400 \mathrm{~kg} / \mathrm{m}^{3}$.

The total load effect is described by $K_{E} \cdot(G+Q)$, with $K_{E}$ the model uncertainty for the load effect, $G$ the permanent load, and $Q$ the imposed load [19]. The model uncertainty $K_{E}$ is described by a lognormal distribution with a mean equal to 1 and a $\mathrm{COV}$ of 0.10 . The dead load is modelled by a normal distribution with a mean equal to the nominal dead load $\left(\mathrm{G}_{\text {norm }}\right)$, and a COV of 0.1 . The live load effect $\mathrm{Q}$ is modelled by a Gamma distribution. For typical occupancies (office, residential), the mean live load can be taken as 0.2 times the nominal, with a COV of 0.60 for large load areas $\left(>200 \mathrm{~m}^{2}\right)$. For the columns analysed in this paper, $\mathrm{G}_{\text {norm }}$ is equal to dead load plus superimposed dead load (6.9 $\mathrm{kPa}$ in total) while the $\mathrm{Q}_{\text {norm }}$ is equal to live load $(3 \mathrm{kPa})$. The two columns are assumed to be located at the ground floor of a five story building. Column A is subject to a gravity load from a tributary area of $7 \mathrm{~m} \times 3.5 \mathrm{~m}$ while Column $\mathrm{B}$ is subject to a gravity load from a tributary area of $7 \mathrm{~m} \mathrm{x} 7 \mathrm{~m}$.

The retention factor of concrete compressive strength at high temperatures, $\mathrm{k}_{\mathrm{c}, \mathrm{T}}$, follows a weibull distribution, while the retention factor of steel yield strength at high temperatures, $\mathrm{k}_{\mathrm{y}, \mathrm{T}}$, follows a lognormal distribution [20]. The parameters for the two distributions are temperature-dependent variables.

The scenarios with each variable equal to its mean value are taken as the reference cases. The column cover thickness remains as the reference values in the sensitivity studies. The parametric fire model in the Eurocode 1 [21] is used to calculated the gas temperature, with the fire load equal to $420 \mathrm{MJ} / \mathrm{m}^{2}$. For the reference cases, the heat penetration depth $\mathrm{d} 300$ is $49 \mathrm{~mm}$ for Column A and $51 \mathrm{~mm}$ for Column B, and the maximum residual out-of-plane deformation is $3 \mathrm{~mm}$ for Column A and $0.8 \mathrm{~mm}$ for Column B. For each variable, two additional cases were run: one is the column with the target variable equal to its mean value minus one standard deviation and the other one is the column with the target variable equal to its mean value plus one standard deviation; all the other variables equal to their mean values. Table 2 summarizes the absolute value of the variation of the EDP values as the target variable changes from $\mu-$ std to $\mu+$ std, relative to that of the reference case. The percentages listed in Table 6 are the average values for the two example RC columns.

According to Table 2, the opening factor is the most critical variable for $\mathrm{d} 300$, while $\mathrm{d} 300$ is not very sensitive to the thermal conductivity and density of concrete, with the variation percentages less than $10 \%$. The MRODR of the columns is sensitive to the retention factor of the yield strength of steel at high temperatures, model effect, dead load, and opening factor. The variation percentage of MRODR due to the uncertainties in live load is greater than $10 \%$, although not as great as the other variables. Therefore, the following parameters will be included in the probabilistic fire-thermo-mechanical analysis: opening factor, dead load, live load, model effect, and retention factor of the yield strength of steel at high temperatures. The uncertainties from the other variables are ignored in this paper.

Table 2 Relative variation in EDP values associated with variable changes from $\mu-$ std and $\mu+$ std

\begin{tabular}{lrr} 
& $\mathrm{d} 300(\%)$ & MRODR $(\%)$ \\
\hline Opening factor & 54.3 & 18.0 \\
Concrete thermal conductivity & 8.6 & 3.4 \\
Concrete density & 1.2 & 1.2 \\
Model effect & - & 29.6 \\
Dead load & - & 27.9 \\
Live load & - & 11.7 \\
Concrete strength & - & 8.6 \\
Steel strength & - & 37.7 \\
\hline
\end{tabular}




\section{RESULTS OF THE COVER THICKNESS OPTIMIZATION}

The expected repair cost of a column is estimated for a cover thickness ranging from $10 \mathrm{~mm}$ to $70 \mathrm{~mm}$, using the fire loss estimation framework described in Section 2.2. For each cover thickness, the probabilistic analysis is based on 500 calculations with SAFIR [22] for each level of fire load (ranging from $100 \mathrm{MJ} / \mathrm{m}^{2}$ to $2300 \mathrm{MJ} / \mathrm{m}^{2}$ ). In addition, the optimum cover thickness of another relatively slender column is investigated in Section 4.3 to investigate the impacts of column slenderness on the optimum cover.

\subsection{Fragility curves}

Figure 3 shows the failure probabilities of the two columns, as a function of the fire load. The numerical data (dots in Figure 3) were fitted by lognormal distributions. The failure probability is almost zero for fire loads up to $1500 \mathrm{MJ} / \mathrm{m}^{2}$. For fire loads greater than $1500 \mathrm{MJ} / \mathrm{m}^{2}$, as the cover thickness increases, a column becomes less vulnerable to failure first but then may become more vulnerable if the cover thickness is as great as $70 \mathrm{~mm}$. This is because a thick cover can provide adequate protection to the rebar but also decreases the distance between the rebar (lever arm) for bending behavior. Compared to Column A, the failure probability of Column B is lower due to its relatively large section and symmetrical fire exposure.

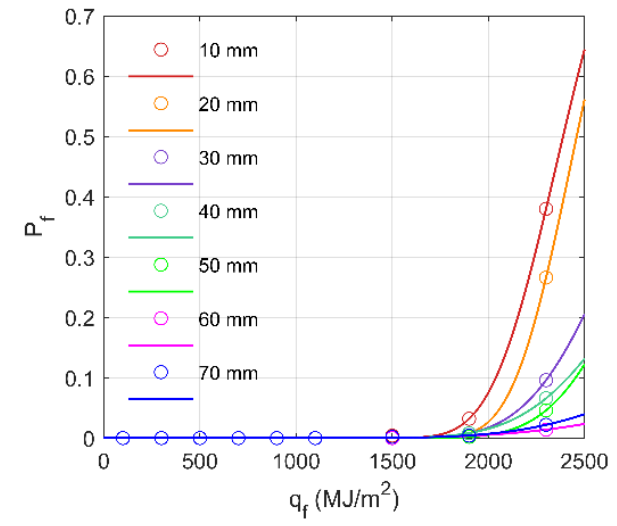

(a) Column A

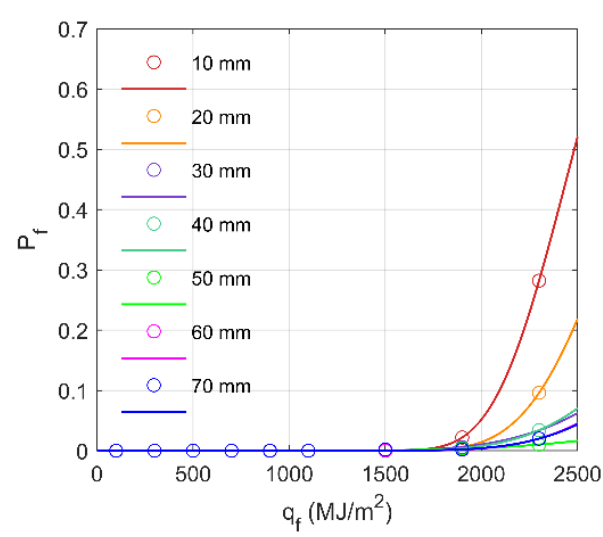

(b) Column B

Figure 3. Failure probability of the two target columns

For nonfailure (nf) scenarios, the distributions of the two EDPs at different levels of fire loads are determined by the probabilistic fire-thermo-mechanical analysis, incorporating the variable uncertainties in opening factor, live load, dead load, model effect, and retention factor of steel yield strength at high temperature. The PDFs of $\mathrm{d} 300$ and MRODR are fitted by the modified gamma distribution and lognormal distributions, respectively. The convolution of the fragility function and the PDF of EDP yields the probability that a column reaches or exceeds a specified damage state (fragility curves). Figure 4 shows the fragility curves of Column A, related to the heat penetration of the $300{ }^{\circ} \mathrm{C}$ isotherm, for cover thickness of $10 \mathrm{~mm}, 40 \mathrm{~mm}$, and $70 \mathrm{~mm}$. The fragility curve of DS1 is unaffected by the change in cover because the lower threshold value of DS1 is a constant value of zero, independent of the cover thickness. Since the lower threshold value of DS2 is 1/10 of the cover thickness that is close to zero [7], the fragility curve of DS2 is close to that of DS1. However, as the cover thickness increases, the fragility curve of DS3 moves away from DS2 towards DS4, while the fragility curve of DS4 slightly shifts to the right side on the $\mathrm{x}$ axis. Figure 5 shows the fragility curves of the two columns related to the maximum residual deformation, for different cover thicknesses. Those curves are from the damage analysis with the limit for the MORDR set as $1 / 700 \mathrm{~h}$. As the cover thickness increases, the fragility curves move to the right since a thick cover protects the rebar from exposure to high temperature. Compared to Column B, Column A is more vulnerable to the out-of-plane deformation due to its relatively small section dimension and unsymmetrical fire exposure. As the cover thickness increases further up to $70 \mathrm{~mm}$, its probability of reaching or exceeding the threshold value is relatively high when the fire load is low (as shown in the blue curve in Figure 5a), since the bending stiffness of a section decreases when the distance between the rebars decreases. However, when the fire load increases further, the advantage of insulation from a thick cover prevails; thus, the probability decreases. 


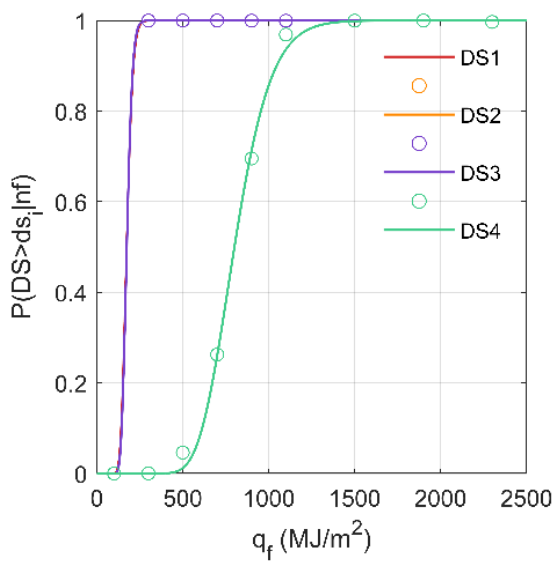

(a) Cover thickness $10 \mathrm{~mm}$

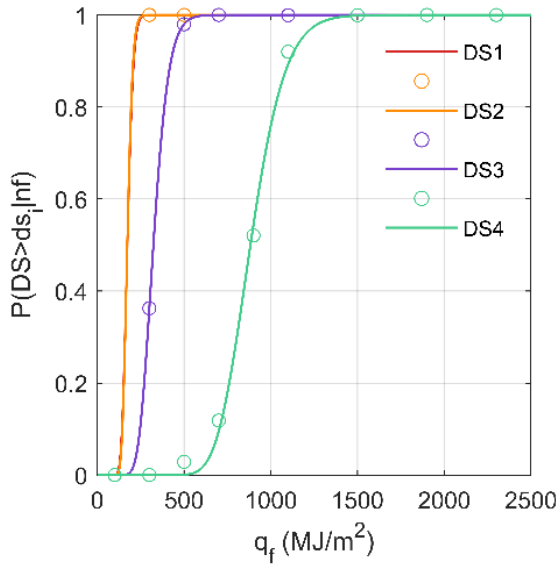

(b) Cover thickness $40 \mathrm{~mm}$

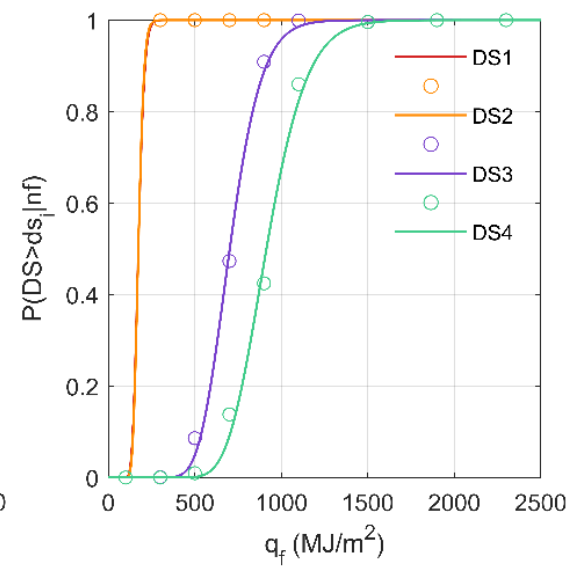

(c) Cover thickness $70 \mathrm{~mm}$

Figure 4. Fragility curves related to the heat penetration of the $300{ }^{\circ} \mathrm{C}$ isotherm (Column A)

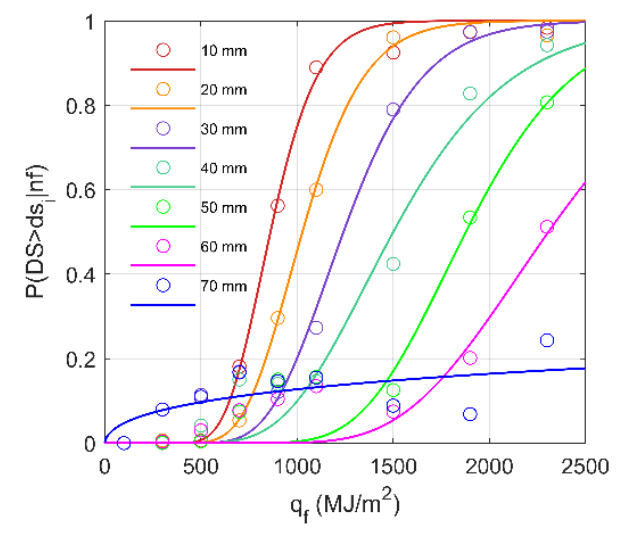

(a) Column A

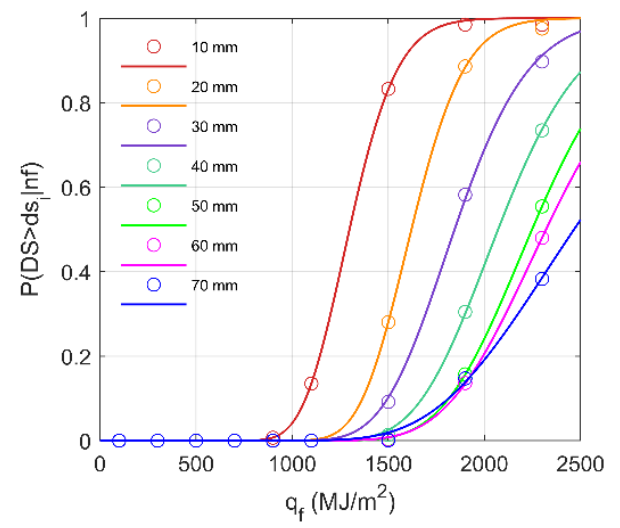

(b) Column B

Figure 5. Fragility curves related to the maximum residual out-of-plane deformation

\subsection{Optimum cover thickness}

Figure 6 shows the variation of the two columns' expected repair cost with cover thickness, conditional on the threshold value for the out-of-plane deformation equal to $1 / 700 \mathrm{~h}$. These curves are calculated from the convolution of the probabilities of a column at different damage states and the PDF of the fire load density, taking into account the costs such as those listed in Table 1. Each curve in Figure 6 represents a level of fire load in a compartment, which depends on a compartment's occupancy type [21]. The fire load is assumed to follow the Gumbel type I distribution; the legends in Figure 6 are the mean values of the fire loads, ranging from $100 \mathrm{MJ} / \mathrm{m}^{2}$ to $1100 \mathrm{MJ} / \mathrm{m}^{2}$.

As shown in Figure 6a, as the cover thickness increases up to $60 \mathrm{~mm}$, the expected repair cost of Column A decreases. For further increase to $70 \mathrm{~mm}$, the repair cost increases slightly. Thick concrete cover could protect the rebar from exposure to high temperatures, thus decreasing the probability that $\mathrm{d} 300$ reaches or exceeds DS3, as shown in Figure 4, and reducing the repair cost significantly since the repair efforts for DS3 requires the supplement rebars. However, as the cover thickness increases to $70 \mathrm{~mm}$, the distance between the rebars decreases, resulting in relatively low bending stiffness of a section and thus a relatively high probability to reach or exceed the MRODR threshold value (as shown in the blue curve in Figure 5a); that is why the repair cost increases for the largest value of cover thickness. Moreover, the expected repair cost increases as the fire load level increases; however, this does not impact the value of the optimum cover thickness which equals to $60 \mathrm{~mm}$ for Column A, regardless of the fire load. It is noteworthy that this optimum is larger than the minimum cover thickness $(40 \mathrm{~mm})$ required for design [23].

Unlike Column A, Column B is heated from four sides and is of a relatively large section, leading to small out-of-plane deformations under fire. Most of the cost of Column B results from the repair efforts associated with the heat penetration of the $300{ }^{\circ} \mathrm{C}$ isotherm. As mentioned before, a thick cover could minimize the 
probability that $\mathrm{d} 300$ reaches or exceeds DS3; that is why the repair cost decreases continuously as the cover thickness increases. However, it is reasonable to expect that the fire loss would increase at some point as the cover thickness increases further beyond $70 \mathrm{~mm}$, due to a reduction in the lever arm.

For both columns studied in this section, the expected repair cost is the highest when the cover thickness is as low as $10 \mathrm{~mm}$ (which is, anyway, an unacceptably low value for other requirements as well, e.g., corrosion). A $10 \mathrm{~mm}$-thick cover is unable to protect the rebar from exposure to high temperature. The degradation of the mechanical properties of rebar at high temperatures leads to a relatively higher failure probability, as shown in Figure 5, thus increasing the expected repair cost. The analyses suggest that the optimum cover thickness from the perspective of fire loss minimization is greater than the minimum cover thickness required for other purposes [23].

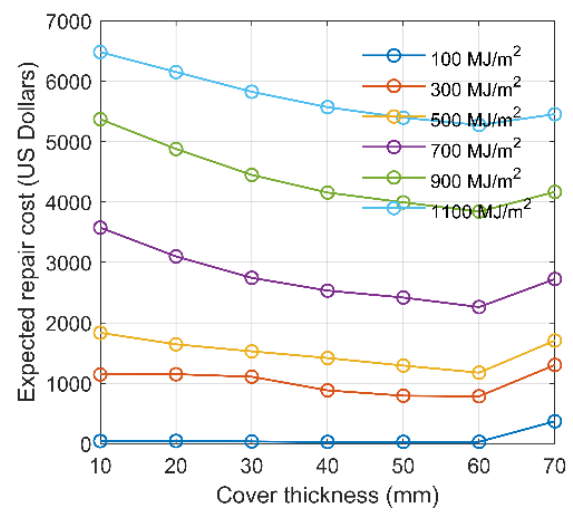

( a ) Column A

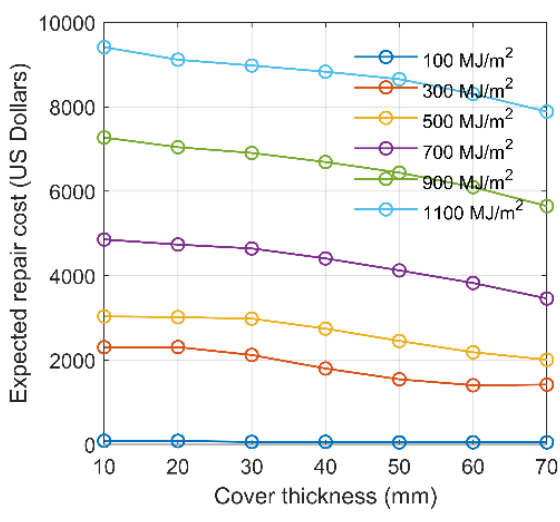

( b ) Column B

Figure 6. Variation of expected repair cost with cover thickness

The optimum cover thickness discussed above is conditional to a threshold value of MRODR equal to $1 / 700 \mathrm{~h}$. As the threshold value increases to a higher level, the repair cost of Column A also decreases continuously as that of Column B due to the limited out-of-plane deformation of the two columns.

\subsection{Effect of column slenderness on the optimum cover thickness}

The studied columns A and B were relatively stocky. This resulted in a limited influence of the residual out-of-plane deformation damage state on the fire losses. In this section, another column was studied to investigate the effect of column slenderness on the optimum cover thickness. The column is $4.76 \mathrm{~m} \mathrm{high}$, simply supported. The section of the column is $300 \mathrm{~mm}$ x $300 \mathrm{~mm}$, with 6 steel bars of $20 \mathrm{~mm}$ diameter and a reference cover thickness of $28 \mathrm{~mm}$. The mean compressive strength of concrete is $31 \mathrm{MPa}$, and the mean yield strength of steel is $462 \mathrm{MPa}$. It is assumed that the column is located in a fire compartment of $14 \mathrm{~m} \mathrm{x} 14 \mathrm{~m}$, with a maximum opening factor of $0.043 \mathrm{~m}^{1 / 2}$. Similar to Column $\mathrm{B}$, this column is exposed to fire on four sides. The fire severity is probabilistically assessed, assuming uncertainty in the opening factor, in addition to fire load being selected as the intensity measure. A stratified sampling method is adopted to select the opening factor for each fire load based on the probability density distribution of opening factor; ten opening factors are selected for each fire load. The axial load imposed at the top of the column remains the same, $650 \mathrm{kN}$, in all the analyses. Table 3 lists the mean repair cost of the column with the reference cover thickness $(28 \mathrm{~mm})$, for the damage related to heat penetration. As the cover thickness changes, the repair cost varies slightly for DS1, DS2, and DS3 while the costs for DS4 remain the same. The repair cost at DS4 is equal to the reconstruction cost of the column in the scenarios where the column has to be replaced due to failure, extensive heat penetration, or extensive out-of-plane deformation.

Table 3. Repair cost for the EDP of heat penetration (d300) for the slender column exposed to fire

\begin{tabular}{lrrrr} 
Cover thickness & DS1 $(\$)$ & DS2 $(\$)$ & DS3 $(\$)$ & DS4 (\$) \\
\hline $28 \mathrm{~mm}$ & 202 & 905 & 1,184 & 3,451 \\
\hline
\end{tabular}

Figure 7 shows the variation of the expected repair cost of the column with cover thickness under different fire load levels, for various threshold values of MRODR. If the threshold value of MRODR is equal to 
$1 / 300 \mathrm{~h}$, the expected repair cost continuously decreases as the cover thickness increases, regardless of the fire load. This is because the importance of out-of-plane displacement is lesser when the tolerance on the threshold is more lenient. For a threshold value of MRODR of 1/500 $\mathrm{h}$ (meaning that the tolerated residual deflection becomes more stringent), a clear optimum cover can be observed for medium fire load levels $\left(500 \mathrm{MJ} / \mathrm{m}^{2}\right.$ to $900 \mathrm{MJ} / \mathrm{m}^{2}$ ), as the expected repair cost decreases first and then increases slightly after an optimum of $49 \mathrm{~mm}$. For fire load levels lower than $500 \mathrm{MJ} / \mathrm{m}^{2}$ and higher than $900 \mathrm{MJ} / \mathrm{m}^{2}$, the expected repair cost continuously decreases with the increase of the cover thickness. This is because low fire load limits the out-of-plane deformation while high fire load requires a thick cover to protect the rebars, thus the advantages of insulation from a thick cover prevail in both cases. As the threshold of MRODR decreases further to $1 / 700 \mathrm{~h}$, the decreasing-increasing trend of the expected repair cost becomes more evident for the three fire load levels, $500 \mathrm{MJ} / \mathrm{m}^{2}, 700 \mathrm{MJ} / \mathrm{m}^{2}$, and $900 \mathrm{MJ} / \mathrm{m}^{2}$. The optimum cover thickness is $42 \mathrm{~mm}$ for the three levels of fire load. Similar to the slender column, Column B is also exposed to four side fire. However, due to its relatively large section dimension and relatively small height, the expected repair cost of Column B does not have a decreasing-increasing trend even when the threshold value of MRODR is equal to $1 / 700 \mathrm{~h}$.

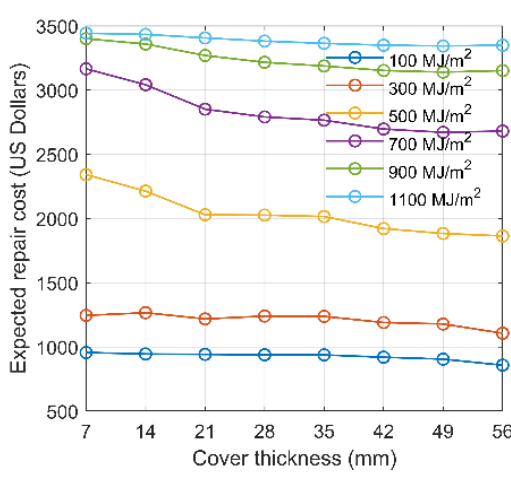

(a) $1 / 300 \mathrm{~h}$

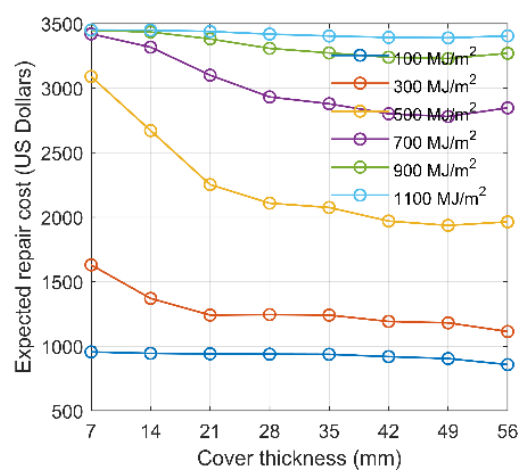

(b) $1 / 500 \mathrm{~h}$

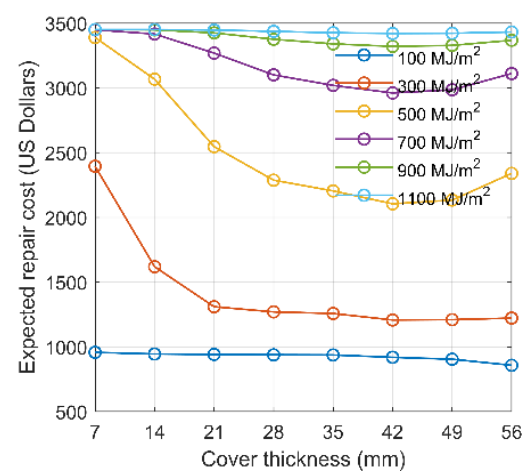

(c) $1 / 700 \mathrm{~h}$

Figure 7. Variation of expected repair cost with cover thickness for the slender column

\section{CONCLUSION}

This paper incorporated a method for probabilistic fire loss estimation of reinforced concrete structures into a lifetime cost optimization framework to optimize the cover thickness with respect to fire response. Without considering the impact of other cost components in the cost-benefit analysis, the cover thickness of several columns was optimized based on the expected probability of failure and repair cost after a fire event. The expected repair cost accounted for the cost of repairs due to heat penetration in the section and residual out-of-plane deformations, as well as the cost for replacement in case of failure. These cost components vary with the variation of cover thickness. The optimum thickness is achieved by balancing the cost components across the range of expected fire events, as characterized by the fire load as the intensity measure. The optimum is also sensitive to assumptions on repair actions, such as on the tolerance for the acceptable residual out-of-plane deformation. For large values of this tolerance, the cost continuously decreased with an increase in cover thickness. Compared to stocky columns, a slender column that experiences more out-of-plane deformation has a smaller optimum cover thickness. The optimization in this paper only focuses on the repair cost of isolated columns. Future works will seek to include more damage characteristics, e.g., residual axial deformation will be incorporated into the fire loss estimation of a column; more cost components in Eq. (1); and to conduct the optimization of design parameters at the scale of a whole building, the importance of which has been emphasized in [24].

\section{REFERENCES}

1. Van Coile R, Hopkin D, Lange D, Jomaas G, Bisby L. The Need for Hierarchies of Acceptance Criteria for Probabilistic Risk Assessments in Fire Engineering. Fire Technol 2019;55:1111-46. https://doi.org/10.1007/s10694-018-0746-7. 
2. Rackwitz R. Optimization - the basis of code-making and reliability verification. Struct Saf 2000;22:2760. https://doi.org/10.1016/S0167-4730(99)00037-5.

3. De Sanctis G, Fontana M. Risk-based optimisation of fire safety egress provisions based on the LQI acceptance criterion. Reliab Eng Syst Saf 2016;152:339-50. https://doi.org/10.1016/j.ress.2016.04.001.

4. Van Coile R, Caspeele R, Taerwe L. Lifetime cost optimization for the structural fire resistance of concrete slabs. Fire Technol 2014;50:1201-27. https://doi.org/10.1007/s10694-013-0350-9.

5. Van Coile R, Gernay T, Hopkin D, Elhami Khorasani N. Resilience targets for structural fire design: An exploratory study. 17th Int. Probabilistic Work., Edinburgh, UK: 2019.

6. Balogh T, Vigh L. Optimal Fire Design of Steel Tapered Portal Frames. Period Polytech Civ Eng 2017;61. https://doi.org/10.3311/PPci.8985.

7. Ni S, Gernay T. A framework for probabilistic fire loss estimation in concrete building structures. Struct Saf 2021.

8. Rosenblueth E, Mendoza E. Reliability Optimization in Isostatic Structures. J Eng Mech Div 1971;97:162542.

9. Fischer K. Societal decision-making for optimal fire safety. ETH Zürich, 2014. https://doi.org/https://doi.org/10.3929/ethz-a-010243009.

10. Hopkin D, Fu I, Van Coile R. Adequate fire safety for structural steel elements based upon life-time cost optimization. Fire Saf J 2020:103095. https://doi.org/10.1016/j.firesaf.2020.103095.

11. Moehle J, Deierlein G. A framework methodology for performance-based earthquake engineering. 13th World Conf. Earthq. Eng., Vancouver, B.C., Canada: 2004, p. No. 679.

12. Gernay T, Elhami Khorasani N, Garlock M. Fire fragility curves for steel buildings in a community context: A methodology. Eng Struct 2016;113:259-76. https://doi.org/https://doi.org/10.1016/j.engstruct.2016.01.043.

13. ENV 13670-1:2000. Execution of concrete structures - Part 1: Common. European Standard, 2000.

14. Gordon Group Inc. Concrete \& masonry costs with RSMeans data 2019. 37th ed. Rockland, MA: RSMeans Co; 2018.

15. Applied Technology Council. Guidelines for the seismic rehabilitation of buildings: Example applications. Washington, D.C.: 1997.

16. JCSS PMC. JCSS probabilistic model code part 2: Load models. Joint Committee on Structural Safety; 2001.

17. BS EN 1992-1-2. Eurocode 2. Design of concrete structures - Part 1-2: General rules. Structural fire design. European Standard, 2004.

18. Harith IK. Study on polyurethane foamed concrete for use in structural applications. Case Stud Constr Mater 2018;8:79-86. https://doi.org/10.1016/j.cscm.2017.11.005.

19. Jovanović B, Van Coile R, Hopkin D, Elhami Khorasani N, Lange D, Gernay T. Review of Current Practice in Probabilistic Structural Fire Engineering: Permanent and Live Load Modelling. Fire Technol 2020. https://doi.org/10.1007/s10694-020-01005-w.

20. Qureshi R, Ni S, Elhami Khorasani N, Van Coile R, Hopkin D, Gernay T. Probabilistic models for temperature dependent strength of steel and concrete. J Struct Eng 2020;146:04020102. https://doi.org/10.1061/(ASCE)ST.1943-541X.0002621.

21. BS EN1991-1-2. Eurocode 1: Actions on structures - Part 1-2: General actions - Actions on structures exposed to fire. European Standard. 2002.

22. Franssen J-M, Gernay T. Modeling structures in fire with SAFIR®: theoretical background and capabilities. J Struct Fire Eng 2017;8:300-23. https://doi.org/10.1108/JSFE-07-2016-0010.

23. CSA A23.3-14. Design of concrete structures. Canadian Standards Association. Mississauga, Ontario, Canada. Can Stand Assoc 2014:109-70.

24. Ni S, Gernay T. Predicting residual deformations in a reinforced concrete building structure after a fire event. Eng Struct 2020;202:109853. https://doi.org/10.1016/J.ENGSTRUCT.2019.109853. 